\title{
Personalization dimensions: a conceptual model for personalized information systems
}

\author{
José Luís Reis \\ CEDTUR- CETRAD \\ ISMAI - Instituto Universitário da Maia \\ Maia - Portugal \\ jlreis@ismai.pt
}

\author{
João Álvaro Carvalho \\ Centro ALGORITMI and Departamento de Sistemas de \\ Informação \\ Universidade do Minho \\ Guimarães - Portugal \\ jac@dsi.uminho.pt
}

\begin{abstract}
Personalization is the adjustment of an information system to the preferences or needs of a user. Personalization can contribute to the improvement of customer relationship or of organizationalefficiency. This article presents a conceptual framework that addresses several personalization issues, such as: personalization levels; implementation levels; personalization dimensions; levels of personalization; levels of implementation and system integration of personalization with personalization dimensions.Based in a practical application, the article also proposesrecommendations to Information Systems Technologies (IST) professionals involved in decisions, regarding the development of personalization dimensions in personalized applications.
\end{abstract}

Keywords-personalization, information systems, personalization levels, conceptual model.

\section{INTRODUCTION}

Personalization is becoming common in Web-based services and in organizational Information and Communications Technology (ICT) applications. The personalization of applications and platforms is a complex process, with many issues to be addressed. This article presents a conceptual model that deals with many of the matters faced by personalization specialists, when making strategic and operational decisions about personalization. The model covers aspects such as: personalization levels, levels of implementation, personalization dimensions/variants, costs and integration.

\section{PERSONALIZATIONAND PERSONALIZATION TYPOLOGIES}

The main goal of personalization in ICT applications (also named as Personalized Applications - PA) is satisfying the needs and preferences of a person (or groups of persons) that use of a particular information system. PA facilitates the interaction among the various actors that cooperate within an organization, and the interaction with information providers and information recipients. PA allows people to have easier access to content and services. PA is called implicit (or adaptive/proactive) if the personalization is done automatically by the system[1]. An example of implicit PA is a system that uses discovers (through the use of collaborative filtering techniques)that a user that likes music from Madonna also likes music from Beyoncé, because he has the same profile of other users that are known to have that preference.
PA is said to be explicit or reactive if user provide information, or make choices, that will allow the system to adapt. For example, the user fills an electronic form stating his reading preferences [2], [3].

\section{PERSONALIZATION LEVELS}

Researchers from the Penn State University, on the assumption, that a personalized company is based on the creation of a long-term relationship with customers, which in addition to the personalized content, personalization should include prices, products, shopping experiences and global relationships. The model proposed by these researchers is based on a set of five levels of personalization, presented below, which increases the difficulty of implementation as they level up [4].

1 - Personalized content. Associate digital content to nondigital components (example: a customized ring tone to a mobile phone) and non-digital personalized content to digital components (example: travel preferences for a hotel or a place on an airplane on a travel site marking).

2 - Personalize prices, packaging, support services, etc. Personalize types of discounts, shipping methods, specific packaging, guarantees or technical support.

3 - Personalize products. The combination of Web personalization with customization of mass production allows, for example, the personalization of computers (Dell, Computer Planet), sneakers (Nike, Puma), clothing (GAP, Levis), cars (Fiat500, Peugeot).

4 - Personalized shopping and consumption experiences. Through online technology, companies can "conduct" customers on an individual basis from the existing information on the characteristics of the profile (example: a typical supermarket has 20000 products and a consumer only chooses from 200, the peapod.com allows a client to select from personalized lists of products and the customer can choose between only these selected products [4]).

5 - Personalize relationships. One way to overcome the fact that only $1.3 \%$ of the buyers through a website return for repeat purchases, personalized the site can increase the number of purchases in each transaction, expanding markets and improving long term relations with customer (example: some airlines allow their passengers that have more frequent access to their favorite places, the meals tailored to their taste, 
a phone number where presumably take less time to be contacted).

\section{IMPLEMENTATION LEVELS}

To be implemented, personalization needs software engines that automate and optimize the interactions between the customers and the suppliers in accordance with their personalized data; like that it is possible to adapt the systems to user needs. These mechanisms can be achieved through the design of systems with appropriate interfaces to users, with personalization and adaptation (tailoring) of interfaces and communication channels, and a dynamic adaptability of ebusiness services and applications [5]. Taking as a reference the work of Christopher Chia and June Garcia, the implementation of personalization can be done in phases with different levels[6]. They have associated with each phase their level of integration of personalization in the information systems components (databases, access control systems, content management systems, etc.), and the respective costs. For each implementation level there are actions associated with personalization, including:

Interaction - conducted through IRC - Internet Relay Chat (for example: Google Talk, ICQ, Skype), private forums, e-mail and social networks (for example: Internet Movie Database in http://www.imdb.com, Barnes and Noble in http://www.bn.com and the DBPL bibliography of computer science in http://www.informatik.uni-trier.de/ ley/db/), that may or may not be integrated with the databases of the organization and can be presented through browsers [3].

Structure - through customization the system allows the user to create a personalized desktop, selecting the options he want (for example: access to email, news, chat systems, research and reporting systems, weather, stock markets, personal agenda or the applications he want to access, etc.). In this case, the system must have an architecture that allows the structure of the screen is changeable according to user preferences creating a unique experience of personalization (for example: MyYaooh, NetVibes, My Excite, JuniorNet). These systems require a prior registration, the identification and definition of a profile defined by completing an online form.

Content - through a Content Management System - CMS it is possible in a dynamic way manage the site or a Web portal content, with the aim of providing the most relevant contents for each user with an attractive way. These CMSbased systems require relatively powerful search engines, or sets of search engines that meet the requests/demands of users and they can customize these or define the form of presentation (layout) of the site [3]. There are several systems with commercial applications that manage this content, such as Wordpress, SIRSI, Joomla, Drupal, etc. [7].

Transactions - with different technologies is possible to obtain real-time recommendations, collaborative filtering, learning flows of clicks (clickstream) data (obtained through agents or bots), guides to support decision-making and advertising targeted/segmented (shown by motors that direct advertising according to user profiles) [8], [9]. This level of personalization requires development of a high level of integration with other data types available in the system (examples: data inquiry, data about user profiles, preferences) which causes impact the customer relationship management systems [10].

\section{THE CONCEPTUAL MODEL BASED IN PERSONALIZATION DIMENSIONS}

The personalization levels model and the implementation feature scales model contain things in common. Analyzing and combining the information contained in these two models, taking into consideration what can be personalized in an information system, as well as the difficulties implementing personalization, it can be obtainedseven personalization dimensions/variants. The difficulty of the implementation of PA is dependent on the level of personalization, for each level are associated personalization dimensions, described as follows [6], [4], [1]:

Relationships - Unlike a transactional situation (a purchase, a conversation, a complaint, etc.), relationship management involves a long-term relation. Personalized Web sites require integration with various components of an information system, particularly with the databases containing the historical records of transactions and preferences.

Transactions/consumer experiences - Through collaborative filtering techniques and analysis of clickstream are created recommendations systems that allow the user to make best decisions suited to their preferences when he makes transactions (for example:purchases or access to information) [11].

Products - Personalization in the world of bits (Web) and in the world of atoms (physical stores), can be made including differentiating elements in the product that allows to associate it to an individual consumer or buyer making it unique (put their name, favorite color, a photo, a message, etc.).

Structures/interfaces - The environment, in which the user moves in their day-to-day, is made up increasingly of electronic components (computers, mobile phones, kiosks, $\mathrm{TV}$, tablets, etc.). It is increasingly common that systems allow the user to configure the desktop, or sightseeing, according to their preferences, which require the creation of flexible structures and interfaces that allow these settings.

Contents - According to the profile of an individual, it's possible build PA that provides content adaptable to user's characteristics. This content can take many forms (sound, image, voice, text, etc.).

Attributes- Differential pricing, packaging, warranties, etc. in products can be managed by an information system that is able to establish rules in accordance with the specifications of the products and the buyer's characteristics.

Interaction - Systems can manage interactions with different communication channels, and manage links to knowledge bases associated with users and organizations.

Graduated the different variables in the model (cost, difficulty of implementation and integration) we get thepersonalization and implementation levels and the 
personalization dimensions/variants model represented in figure 1.

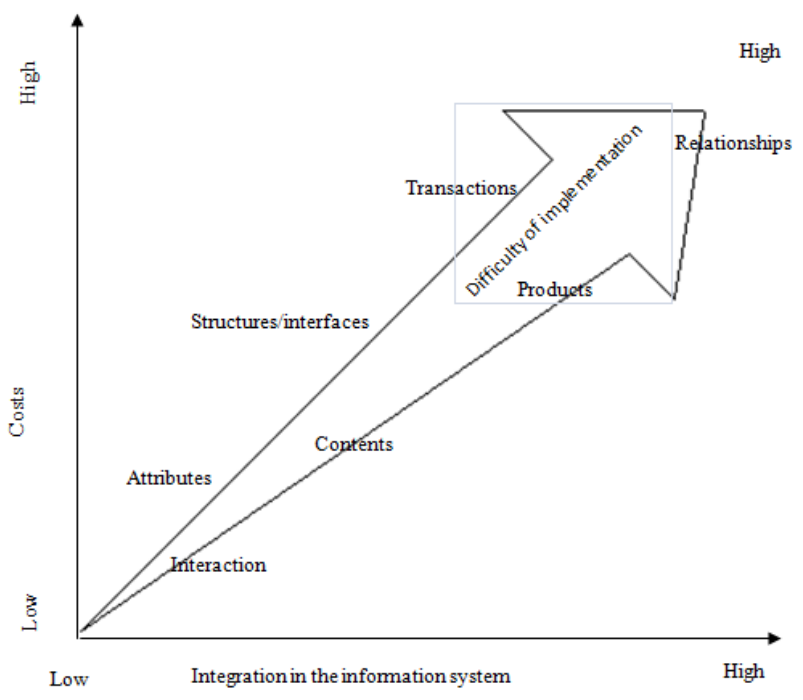

Figure 1 - Personalization dimensions/variants conceptual model

As can be seen in Figure 1, the dimensions/variants conceptual model offer greater personalization difficulty, greater is the difficulty of implementing and integration in the system and higher are the costs. We can conclude that as the personalization level is higher, higher is the cost associated with implementation of a PA.

\section{THE CVRVV PRACTICAL APPLICATION CASE}

Thedevelopment of personalized features inthe extranet systemof the Commission of Viticulture of the Region Vinho Verde (CVRVV), allow checking the validity of the conceptual model that combines the personalization dimensions with the integration in information system and respective cost. This section also can help the IST professionals involved in decisions about personalized applications.

The system called INETSIV (SIV - Wine Information System) allows the institution's relationship with its business community and its municipal delegations. In this section of the work it is described CVRVV, the objectives of personalization in CVRVV, what'spersonalized, the dimensions/variants personalized, theintegration in the information system, and difficulty of implementation and effort costs of personalization in the CVRVV information system [11].

\section{a. The CVRVV}

CVRVV is the entity responsible for the certification of the Portuguese wine products with designation of origin Vinho Verde and Regional Minho. The CVRVV is also responsible for safeguarding the assets of the Region and the institutional promotion inthe markets. The Vinhos Verdes Region has about 20000 producers who have an area of about 18000 ha of vines, with 600 entities authorized to bottle on average $60 \mathrm{x}$ $10^{\wedge} 61 /$ year certificate in about 2000 trademarks in the Region [12]. CVRVV organic structure sets seven working departments with about 60 employees. The departments ensure the normal functioning of the institution, ensuring certification of wine products, protection of heritage designation and institutional promotion of products and brands from Vinho Verde and Regional Minho. There are various software applications to automate the processes involved in certification, with a set of modules which correspond to different applications required for certification management of products. The system contains a set of interfaces, including an Intranet, that enablethe interaction between about 50 internal users and the organization, a Extranet accessible to approximately 600 Economic Agents as well as 45 municipal delegations and an Internet portal available in www.vinhoverde.pt.

\section{b. Personalization objectives in CVRVV}

The project called Web Personalization in CVRVV developed a set of features to improve the way users (Economic Agents and Delegations) interact with CVRVV through the information system. The personalization project allowed implementing a set of personalized features including:

- A system that records how the Economic Agents (EA) accesses different options via the Extranet (INETSIV), noting in particular the selected options, time of use, as well transactions each done. This system allows users to have access to a range of information related how each user uses the different options available on the Extranet.

-System access options available through facilitating elements, including through quick access buttons to the computer applications system.

- A system which allows registration and access to e-mail messages that are personalized according the EA profile.

- Customization the attributes of brands with designation of origin certified by CVRVV in its component Extranet, Intranet and Internet. This system component requires an explicit action by EA to change the information associated with their product brands.

\section{c. Personalization features in the CVRVV information system}

The personalized features of CVRVV extranet INETSIVare explained in a detailed way in the next paragraphs, the costs and labor associated with each feature being presented. The screens of the PA implemented and its personalized features can be seen in the figures presented.

To facilitate the user's access to the applications is recommended to be available personalized quick access buttons, which integrate two types of dimensions in the personalization conceptual model; interaction and transactions. This interactions and transactions are established withCVRVV Economic Agents and CVRVV Delegations, with personalized quick access buttons, developed under the personalization project - see buttons marked with a square in the left top part of Figure 2. 


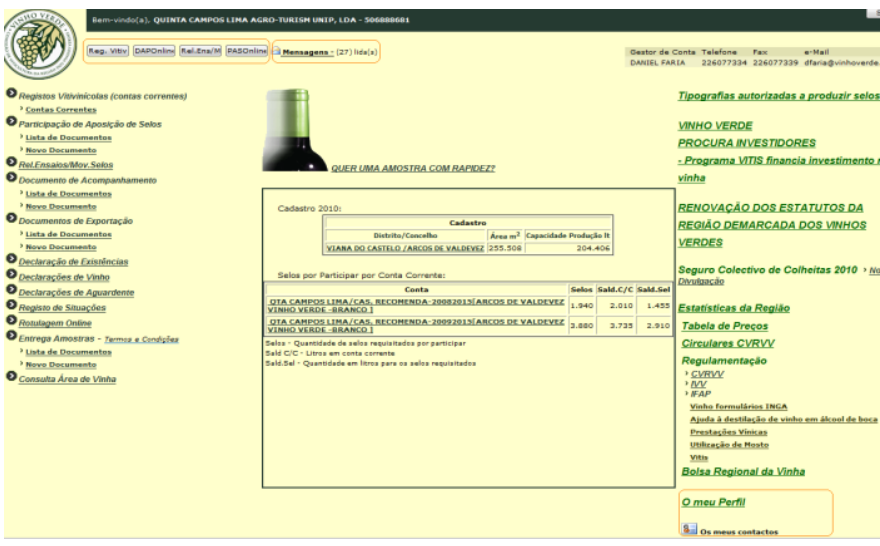

Figure 2 - Main screen of the CVRVV extranet

Personalized content in email box messages and adequate information on the main screen with useful and relevant information to users - see the square in the middle of Figure 2.

Customize brands attributes. Each product brand can have multiple garments with different components (labeling, for example labels, back labels, chokers, etc.) associated with the type of packaging (bottles) of different capacity's, the validation of this information is taken in intranet by CVRVV employees, and the holders of trademarks (Economic Agents), may alter in the CVRVV extranet, how the general public can see these garments in CVRVV internet portal, this is the personalized functionality in the information system - see Figure 3.

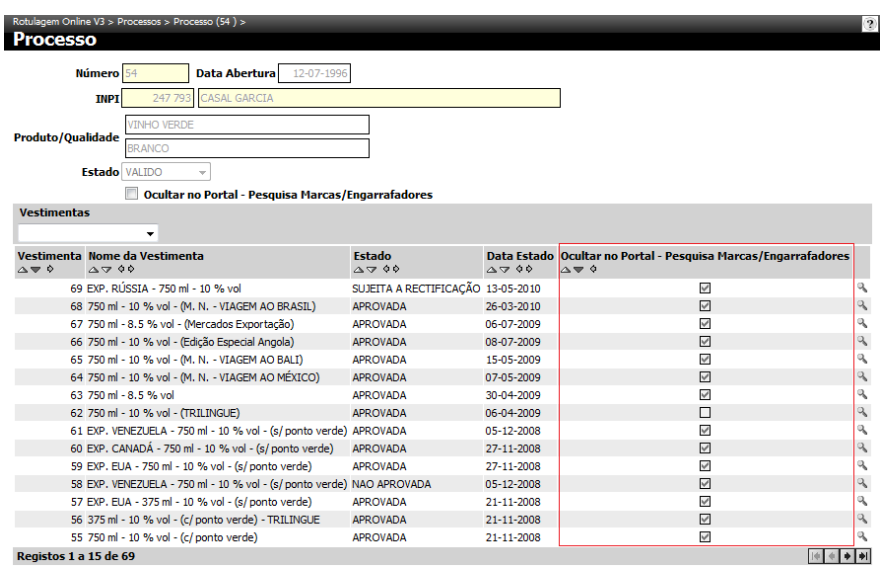

Figure 3 - Screen to customize de product brand

To implement these personalized features where adapted personalization implicit types in most of the functionality's, with the exception of customizing of the brands attributes and selection the preferences regarding quick access buttons, which require user intervention with explicit personalization.

\section{d. The personalization dimensions conceptual model in $C V R V V$}

The CVRVV is a nonprofit entity; however, as for-profit organizations the strategic guidelines for CVRVV the information systems level of development, are aligned/integrated in the strategic objectives of the organization.The CVRVV made a bet on the optimization of their business processes through electronic from the mid-80s, investing on tools that have been evolving into a Webbasedenvironment from 1996. The investment in management tools that support the business processes of CVRVV via electronic means allowed dematerialize most documents required to manage the CVRVV. Hence, it was not difficult to understand that personalize some functionality's on the CVRVV system is a way to improve the interaction of the organization with its members. In the assessment that was made in 2005, it was considered that personalization brings benefits for business community and to the CVRVV because, on one hand the business community has facilities that enablerthe use of the system, and CVRVV benefits of their investments to provide differentiated services.

The analysis of the costs and benefits of personalization, coupled with personalization dimensions/variants implemented in CVRVV system allows us to conclude the following [13]:

- The quick access buttons involvedtwo personalized dimensions; interaction and transactions. The main benefits are improving the service and the way of communication with CVRVV members, improve response rates and satisfaction. The main costs are investments in technology and in the information system development(50 $000 €$, two manpower one 60 days and other one during 80 days). The transaction dimension involve resources for recording the moreused options in the system over time, through the registration of clickstream, as well as quick access buttons ordered by most used options available (interaction dimension), giving the user the possibility to change these same options, as well as their order in which the buttons appear.

- In the dimension attributes (customize of interface brands), the greatest benefits are to improve service to members of CVRVV and improve customer satisfaction through service differentiation. The highest costsare those associated with investments in technologies, significant costs mainly by the need for changes in the WAM (Web Access Management - external service company during 15 days - 15 $000 €)$ platform to support the needs required in the implementation of this personalization variant(two manpower, one 35 days, the other one 30 days - $30000 €$,) and investments in training of users (to access these feature, Economic Agents have specific training needs $-1500 €$ ).

- In the dimension/variant content (personalized email box messages and statistics), the main benefits are communicating content tailored to each member, improving communication and satisfaction through differentiation of the service provided by CVRVV. The main costs are investments in technology and in theinformation system development (turn out to be significant, mainly for allocating hours of human resources for the personalization project,two manpower one during 40 days, the other during 60 days $-38500 €$ )and investments in training of users (the access to these personalized feature are very intuitive, with no specific training needs).

The analysis of personalized functionality's described in the previous sections on the difficulties of implementation and integration into the information system, and the costs associated, crossing the dimension conceptual model shown in 
Figure 1, we see that the feature "fast access buttons" is that had more costs, and had more difficulties in implementation and system integration, because is the one that has two levels of dimensions and one of them (transactions) higher than all others, the customization functionality of the brands with the variant attributes would have been cheaper, as would be predicted by the analysis of Figure 1, if it had not existed the need for an external service company. This project proves, in a clear way, that the proposed model is a good helper for the planning and management of personalized information systems projects.

\section{RECOMMENDATIONS}

The implementation of a personalized system goes through several steps. That addresses issues such as: evaluate the business model;define the processes that allow personalization; define personalization types and levels according to the targets; define the dimensions of personalization. The personalization team, and particularly its coordinator, must have clear ideas on those issues so thepersonalization process can be well succeeded.

Figure 1 presents a conceptual model of personalization dimensions/variants, that can be used to guide managers of personalization projects through the decisions that have to be made during a personalization process, especially the decisions on what to personalize(relationships, transactions/user experiences, products, structures/interfaces, content, attributes, and interaction).These decisions will take into account the benefits and the costs of personalization. In what concerns the costs, both direct and indirect costs should be expected. Personalization will bring additional complexity to processes and to IT platforms and will also increase demands on the level of integration among IT applications.

\section{CONCLUSIONS AND FUTURE WORK}

This article presents a synopsis of relevant information about information system personalization. This has been done by collecting information from different sources and presenting them in a consolidated way. The result can be described as a conceptual framework that can help ICT managers to define the best dimension strategies for the development of personalized information systems.

Several new paths to personalized systems can be envisaged, such as: software support for mobile devices; big data analysis to processing individual information (individualization of information); new forms of user authentication integrated into multiple sites; the possibility of transactional information as a result of user experiences, might be crossed (with the authorization of their own) by various organizations, force companies to turn to sources of information from the cookies, clickstream analysis, transaction information, emails, e-forms, etc. which will add demographic and psychographic information vital to the organizational marketing communications.

Despite the limitations of this work, particularly related to a validation based on a single study, the results presented are a stable base for the activities of IST professionals involved in decisions regarding the adoption of personalization or involved in PA projects.

\section{REFERENCES}

[1] Fan, H., \& Poole, M. S. (2006). What Is Personalization? Perspectives on the Design and Implementation of Personalization in Information Systems Journal of Organizational Computing and Electronic Commerce, 16(3-5). pag 179-202.

[2] Anand, S. S., \& Mobasher, B. (2005). Intelligent Techniques for Web Personalization. USA

[3] Perugini, S., \& Ramakrishnan, N. (2002). Personalizing Interactions with Information Systems. Department of Computer Science. Blacksburg - Virginia

[4] Rangaswamy, A., \& Balakrishnan, A. (2002). From Many to One: Personalized Product Fulfillment Systems. The Penn State eBusiness Research Center. USA

[5] Toth, K., \& Nagboth, S. R. (2002). Constraint-Based Personalization Model: Multi-Channel Messaging. Dept. of Computer Science, Oregon State University. Oregon, USA

[6] Chia, C., \& Garcia, J. (2002). The personalization challenge in public libraries: perspectives and prospects. Retrieved on 15.12.2013, from PLIN - Public Libraries International Network: www.publiclibraries.net/html/x_media/pdf/personalisation_engl.pdf

[7] Shreves, R. (2008). The 2008 Open Source CMS. (water\&stone, Ed.) Retrieved on 14.12.2008, from The Open Source CMS experts: http://www.waterandstone.com/downloads/2008OpenSourceCMSMarke tSurvey.pdf

[8] Black, J., Downes, K., Field, F., Mozdzanowska, A., \& Steel, K. (2006). Technologies:, The Metaphors of Emerging Unpacking the disconnects between the "what" and the "how" in the world of "online shopping". (M. E. Technologies, Ed.)

[9] Markov, Z., \& Larose, D. (2007). Data Mining The Web - Uncover Patterns in Web Contente, Structure, and Usage. John Wiley \& Sons. USA

[10] Dionísio, P., Rodrigues, V., Faria, H., Canhoto, R., \& Nunes, R. (2009). $b$-Mercator - Blended Marketing .Dom Quixote. Portugal

[11] Reis, J., \& Carvalho, J., (2013). Aspects that contribute to the success of personalized Web applications, Advances in Intelligent Systems and Computing, Springer, Volume 206, 2013, pp 421-432, Germany

[12] CVRVV, (2014), Número de produtores de vinho verde, Retrieved on 24.01.2014,from www.vinhoverde.pt/pt/recursos/estatistica/graficos.asp

[13] Reis, J., (2012), Sistemas de Informação Personalizados, Universidade do Minho, Doctoral Thesis, http://hdl.handle.net/1822/20773, Guimarães, Portugal 